\title{
Editorial
}

\section{Buying Health: The Costs of Commercialism and an Alternative Philosophy}

\author{
Larry R. Churchill ${ }^{1, \star}$, Shelley C. Churchill ${ }^{2}$ \\ ${ }^{1}$ Center for Biomedical Ethics and Society, Vanderbilt University, Nashville, USA \\ ${ }^{2}$ Simple Health Change, Nashville, USA
}

Received: 1 July 2013, Accepted: 11 July 2013, ePublished: 11 July 2013

\begin{abstract}
This paper argues that commercial forces have steadily encroached into our understanding of medicine and health in modern industrial societies. The impact on the delivery of personal medical services and on common ideas about food and nutrition is profound and largely deleterious to public health. A key component of commercialization is reductionism of medical services, health products and nutritional components into small, marketable units. This reductive force makes both medical services and nutritional components more costly and is corrosive to more holistic concepts of health. We compare commercial and holistic approaches to nutrition in detail and offer an alternative philosophy. Adopting this alternative will require sound public policies that rely less on marketing as a distribution system and that enfranchise individuals to be reflective on their use of medical services, their food and nutrition choices, and their larger health needs.
\end{abstract}

$\mathrm{I}$ $\mathrm{t}$ is increasingly hard to find areas of life into which commercialism has not encroached. This hegemony of commercial forces over other ways of thinking and judging value is characteristic of Western industrial societies, but perhaps most evident in the United States. The basic idea is that markets can solve most of our problems and that commercialization should be the model for all sorts of social exchanges. It has long been touted as a more efficient way to distribute goods and services, even when it is more expensive, such as in health care. But because modern societies tend to think of markets as the natural way to do things, commercialization becomes the default approach to organize and manage exchanges of all sorts, both in public and private life.

The dominance of commercial exchanges is described and critically examined in a recent book by Micheal J. Sandel, What Money Can't Buy (1). Sandel provides details about transactions we ordinarily think are immune to market influences, for example, such practices as buying prison upgrades, paying someone to carry a fetus, cash for weight loss, buying the cell phone number of one's doctor, or the "terrorism futures market," essentially a betting pool on when and where terrorist attacks will occur. But even disregarding these bizarre examples, it is clear that commercial forces have bored deep into our sensibilities, affecting our sense of self and community and our understanding of what constitutes the "good" in our lives. This essay is an exploration of some of the ways commercial thinking and a commercial sense of ourselves have displaced more holistic understandings of health generally, and nutrition and food in particular.

\section{The medicalization of health}

The growing power of commercial forces in medical practice is one obvious place to begin our analysis. Two former editors of the New England Journal of Medicine have written important books on this phenomenon. Marcia Angell's The Truth about Drug Companies details the power of big pharma over the prescribing habits of physicians (2). Jerome Kassirer's On the Take describes the corrupting influence of big business generally, including the reach of commerce into medical research, education and practice patterns well beyond commercial pressures on prescribing (3).

The corrosive effects of advertising and commercialization are more damaging because of the ways modern societies have come to rely on physicians, and are often made less healthy in the process. Here it is important to remember that commercial forces not only respond to markets, but work diligently to create markets. A prime example is pharmaceutical advertising to the public. Marketing surveys have consistently shown that drug advertisements influence patients to ask their physicians about drugs that have been promoted, especially those featured on television and radio. And such patient requests lead to more prescriptions for the advertised product. So while direct-to-consumer advertising is defended by pharma as patient education, the result is more people taking more drugs, requesting expensive drugs still under patent when a generic would be as effective, and more generally substituting pharmaceutical fixes for healthy lifestyles. "I take my Lipitor so I can eat what I want" is a strategy frequently voiced and broadly endorsed, and has many variations.

It is often said that physicians know a great deal about disease but little about health. Our claim is different and more worrisome. We argue that modern ideas of health are largely driven by a consumer market model, and frequently reduced to a matter

${ }^{\star}$ Corresponding author: Larry R. Churchill; Email: larry.churchill@vanderbiblt.edu 
of acquiring personal medical services, which are themselves highly commercialized. Health itself, our ideas about where it comes from and how to keep or improve it, has fallen under market hegemony. Health, in this formulation, means periodic medical exams for reassurance, counselling about risk factors, and subsequent consumption of products largely available from physicians or recommended by them-surgeries, prescription drugs, vitamin supplements and a variety of personal services all available for the right price. Even general health checks by physicians are known to lead to overdiagnosis, iatrogenic overtreatment and needless expense. The marketing of whole genome sequencing and whole body scanning promoted by testing and equipment companies accentuate this pattern of high costs, dubious health benefits and substantial hazards.

This is worrisome because most of the things that make us healthy and keep us healthy are cheap and largely available without professional help or commercial prodding. We are not claiming that medicine is not sometimes necessary, and even life-saving. Appendectomies, emergency procedures following motor vehicle accidents, for example, or antibiotics for infections can have profound benefits. Yet these few, dramatic instances seem to have blocked out the larger picture. Most of the health gains over the last century both in Western societies and globally have resulted not from medical interventions but from improved public health-better sanitation and nutrition, safe housing, broader education and greater employment opportunities. Medical successes have been overplayed, with the result that we rely too often on experts, take less responsibility for ourselves, see our health problems as largely technical and mechanical in nature, and look to whatever scientific innovations markets can offer for answers. The final indication of the power of this model for health is in the language. We are now encouraged to think of ourselves as "health consumers," physicians as "providers," and to register our pleasure/displeasure with the services through "satisfaction surveys." The logic of shopping for medical services is now little different from shopping at Walmart, except that at Walmart the pricing is transparent and there is no pretense of trust beyond the barest commercial exchange. Despite all the fiduciary rhetoric of health care, the industrial production and market-consumption model for medical services has won the day over the vocational service model. The result is a notion of health and health care that is damaging to health professionals, their patients and public health generally.
Early in this essay we spoke of displacement of holistic notions of health. With the commercialization of health goes a certain kind of reductionism. Markets can grow and flourish when products and services are broken apart and sold separately, with little awareness or concern for the loss involved. Nowhere is this more evident than in the food industry, to which we now turn. While the commercialization of medicine is a problem, the commercialization of food has far greater health consequences.

\section{The commercialization of nutrition}

Just as with medical services, the increasing commercialization of nutrition is alarming. We are dangerously close to marketbased perspectives dictating our understanding of nutrition and our relationship with food as nourishment. Food and nutrition are critical inputs to the process of getting and being healthy. Humankind has experienced this for generations while benefiting from greater access to a variety of whole foods across global populations. Joshua Rosenthal, in his book Integrative Nutrition, sees food and nutrition as one of the fundamental areas that nourish us and sustain a state of health (4). Other areas nourish or feed us such as exercise, relationships, career and spirituality. Nutrition, according to Rosenthal, works in concert with these other areas and understanding nutrition as one, but not the only input to a continual interplay is key-the process of health is a constant tweaking of these inputs to discover the harmony between all five that creates lasting wellness. Commercialization implicitly opposes this more integrative viewpoint. Commerce rewards over-simplification and common denominator thinking precisely because this allows for bit-sized marketing and move-the inventory tactics that feed the bottom line. Piece-meal pricing for increased profits has been a part of health care in market societies for some time, as is apparent feefor-service delivery of medical services.

While food has been commercial for decades, what is increasingly prevalent is the commercialization of nutrition itself, with "nutritious food" as the downstream product. Success equates to getting the most money from nutrition (and its component parts of vitamins, minerals, protein, fats, carbohydrates and fiber) through the quickest means possible. What is at stake when commerce displaces communal and holistic understandings of nutrition? A great deal, it turns out. Table 1 shows what is lost in this exchange.

When nutrition is commercialized, people default to organizing

Table 1. Commercial and holistic concepts of nutrition

\begin{tabular}{|c|c|}
\hline Nutrition as a commercial product & Nutrition as part of holistic health \\
\hline - Seeks profit as the end goal. & Seeks nourishment as the end goal. \\
\hline - $\quad$ Success is selling the most products. & $\begin{array}{l}\text { - Success is the most effective and efficient achievement } \\
\text { of a healthy state of being. }\end{array}$ \\
\hline $\begin{array}{l}\text { - Food is most valuable broken into "nutritional" parts. } \\
\text { (For example: take calcium out and add it into other things or } \\
\text { sell as a supplement, etc.) }\end{array}$ & $\begin{array}{l}\text { - Food is most nourishing when eaten whole. } \\
\text { - (For example: just eat the broccoli, the blueberries, etc., } \\
\text { as they occur in nature because they work!) }\end{array}$ \\
\hline $\begin{array}{l}\text { - Nutrition parts and pieces extracted and consumed in isolation, } \\
\text { are just as effective as its natural state. } \\
\text { (For example, the idea that calcium in tablets will work like } \\
\text { whole foods.) }\end{array}$ & $\begin{array}{l}\text { - Nutrition works best in its natural state and organic } \\
\text { context. } \\
\text { (For example, getting calcium from } \\
\text { kale, yogurt, or sardines.) }\end{array}$ \\
\hline - Nutrition is a one-size-fits-all checklist. & Nutrition is unique to individuals. \\
\hline - Nutrition is a static formula with discrete components. & $\begin{array}{l}\text { Nutrition is an input to a continuous process - getting } \\
\text { healthy. }\end{array}$ \\
\hline
\end{tabular}


and managing nutrition as dictated by market forces-ones that certainly do not have nourishment as a priority. In commerce, advertising is the vehicle and profit is the driver. Education about the fundamentals of health and wellness takes a back seat. When we buy what we are constantly marketed toward, then, in turn, praised by our parents, physicians and other "experts," it only reinforces the displacement of ourselves as the ultimate authority of our own health. This may be the biggest, costliest and most disturbing implication to the commercialization of nutrition - the loss of individual discovery and observation as the most tried and true method of becoming healthy. In the end, we cannot really buy our way to good health. We have to discover it.

\section{An alternative: recovering our health}

Health is not a static state, acquired through carbon copy templates and standardized services. It is neither the purview of physicians who typically understand little about it, and even less so the commercial suppliers of foods and supplements who reduce it to isolated components. Health is a complex process with multiple inputs, unique to each person on the planet. Recovering our health means first of all understanding that the essential components of health reach well beyond medical services and nutrition as these are usually understood. As Rosenthal says, the things that nourish us are not only whole foods, but also exercise routines, fulfilling careers, close relationships and spiritual practices. Within these broad strokes of health, each person must find their own balance, and this balance can only be known through attention to ourselves, observing what feeds us and what poisons our lives. The responsibility for knowing what uniquely nourishes us is ultimately ours. The corrosive power of commercialization lies precisely in its deflection away from this critical capacity to observe, reflect and finally understand our own health.

In the end we cannot outsource or buy our way to the answer. These strategies alienate us from the sources of our own wellbeing and make us passive and compliant consumers. Instead we must dare to think for ourselves, speak with people we trust and share experiences, but most of all develop a practice of keen observation, noticing how much of our health lies within our own hands. Then we can demand from our governmental leaders attention to the social inputs that enable individuals to flourish: policies that enable access to whole foods, that guarantee clean air and water, that promote safe neighborhoods, and especially policies that provide universal education. The choice is ours.

Ethical issues

Not applicable.

Competing interests

The authors declare no competing interests.

Authors' contributions

Both authors contributed to the conception and the design of the manuscript. Both authors fully participated in initial drafting and final revision of the manuscript.

\section{References}

1. Sandel M. What Money Can't Buy. New York: Farrar, Straus and Giroux; 2012.

2. Angell M. The Truth about Drug Companies. New York: Random House; 2004.

3. Kassirer J. On the Take. New York: Oxford University Press; 2005.

4. Rosenthal J. Integrative Nutrition. New York: Integrative Nutrition Publishing; 2008. 